\title{
Intra-adrenal mechanisms in the response to chronic stress: investigation in a rat model of emotionality
}

\author{
O Kosti, P W Raven ${ }^{1}$, D Renshaw and J P Hinson \\ Centre for Endocrinology, William Harvey Research Institute, Barts and The London, Queen Mary's School of Medicine and Dentistry, QMUL, First Floor, \\ John Vane Science Centre, Charterhouse Square, London EC1 M 6BQ, UK \\ ${ }^{1}$ Metabolic and Clinical Trials Unit, Department of Mental Health Sciences, Royal Free and University College Medical School, UCL, London, UK \\ (Requests for offprints should be addressed to J P Hinson; Email: j.p.hinson@qmul.ac.uk)
}

\begin{abstract}
The exploratory behaviour of the genetically derived Maudsley rat model of emotionality has been well characterized. Maudsley reactives (MR) present with more 'anxious-like' behaviour than Maudsley nonreactives (MNR). Although this behaviour is assumed to be associated with altered adrenocortical function, the few studies addressing this issue have produced inconsistent findings. We therefore set out to investigate the adrenal endocrinology of the MR and MNR strains. Control Wistars, the ancestors of the Maudsleys, have been used for the first time to set the baseline for all the experiments carried out. It was found that the MNR strain had a significantly blunted adrenocorticotrophic hormone (ACTH) response to restraint stress compared with Wistars, but a normal corticosterone response. Conversely, the MR had a significantly exaggerated ACTH response to restraint stress,
\end{abstract}

but a normal corticosterone response. This finding suggested that the MR adrenal is less sensitive to ACTH than the MNR. This was confirmed by investigating the corticosterone dose-response to ACTH in adrenals from the two strains incubated in vitro. Several possible intraadrenal regulators were investigated, but the only significant molecular difference in the adrenal glands from the two strains was the level of expression of neuropeptide $Y$ (NPY), which is known to be a stress-responsive peptide in the adrenal. We propose that intra-adrenal NPY is responsible for blunting adrenocortical responses to ACTH stimulation in the MR strain. The observed changes in adrenal NPY suggest that this rat strain may serve as a model of chronic stress, with the MR phenotype representing maladaptation.

Journal of Endocrinology (2006) 189, 211-218

\section{Introduction}

The Maudsley reactive (MR) and nonreactive (MNR) rat strains were originally selected for differences in open-field defecation, an action reflecting 'fearfulness' (Broadhurst 1957). Since MRs defecate the most, while MNRs defecate the least or not at all, the MRs are often described as 'emotional' and 'fearful' compared with the MNRs. Although the Maudsley model has been around for over four decades, and its exploratory behaviour has been thoroughly investigated (for review, see Blizard \& Adams 2002), little is known about its endocrinology and how this reflects the emotional phenotype. This seems surprising given the underlying assumption of a relationship between emotionality and adrenocortical function, which came from the observation that there were differences in adrenal weights between rats bred for high and low emotionality (Yeakel \& Rhoades 1941) and between different strains which expressed varying levels of emotionality (Ader et al. 1967). It is remarkable that there has been little attempt to verify this assumption, and in a recent review of the Maudsley strains, their endocrinology is mentioned only under 'miscellaneous findings' (Blizard \& Adams 2002).

The only studies directly to address the question of a relationship between emotionality and adrenal function reported no differences in basal or stressed plasma corticosterone or adrenocorticotrophic hormone (ACTH) levels between the MR and MNR strains after short-duration open-field test and swim stress (Abel 1991). Similarly, foot shock, a more intense acute stress, was found to elevate plasma corticosterone and ACTH levels to a comparable extent in both strains, while stressed prolactin levels were higher among the MR animals (Blizard \& Adams 2002). There have been several studies in vivo, comparing the responsiveness of the hypothalamic-pituitary-adrenal (HPA) axis to stress in different rat strains, and it has been concluded that the differences seen are mostly at the level of the adrenal cortex (Gomez et al. 1996). In vitro studies have also shown clear strain differences in basal steroid secretion and in adrenal responsiveness to stimulation, although there was no attempt to correlate these 
differences with emotionality (Vinson et al. 1978). It seemed likely from these reports that there may be more subtle differences in adrenocortical responsiveness between different strains, bred for high and low emotionality, which may not be reflected in changes in the crude measure of maximal plasma corticosterone levels. To date, there have been no studies addressing the origin of these strain differences in adrenal responsiveness.

To the best of our knowledge, no previous study has compared the behavioural or physiological phenotype of the Maudsley strains with that of control Wistar rats, the ancestors of the Maudsleys. Therefore, it has been difficult to determine which of the strains acts 'normally' (if any) and which reflects characteristics of their genetic predisposition to being 'emotional' (reactives) or 'relaxed' (nonreactives).

The work presented here aims to evaluate the adrenal endocrinology of the Maudsley strains and identify differences in the intra-adrenal regulation of the MR and MNR animals that may reflect differences in their phenotype. This study was designed to compare basal measures of HPA axis activity and to evaluate the response to a stressful stimulus, using a different (longer-duration) paradigm from those previously investigated. In vitro studies were carried out to determine adrenocortical responsiveness to ACTH, and the expression of intraadrenal signalling molecules was investigated in order to determine whether the differences observed may be explained by changes in the expression of melanocortin receptors or other intra-adrenal regulators, such as neuropeptide Y (NPY) (for review, see Renshaw \& Hinson 2001).

\section{Materials and Methods}

\section{Source of reagents}

Collagenase type I was obtained from Worthington Biochemical Corporation (Lakewood, UK); ACTH (1-24) (Synacthen) was obtained from Ciba-Geigy (Horsham, $\mathrm{UK}) ;\left[1,2,6,7-{ }^{3} \mathrm{H}\right]$ aldosterone, mRNA extraction kits and First Strand Synthesis Kits were purchased from Amersham Pharmacia Biotech; and real-time PCR primers and fluorogenic probes were obtained from Sigma-Genosys. All other reagents were obtained from Sigma-Aldrich or from VWR International (Poole, UK).

\section{Animal maintenance}

All animal experimentation was conducted under UK Home Office Licence and local ethical guidelines. All animals used were male, age-matched MR and MNR or control Wistars, bred at Queen Mary University of London and tested for open-field defecation in order to verify the phenotype. The average weight of animals in each group was $382 \pm 22,339 \pm 27$ and $368 \pm 36 \mathrm{~g}$ for the MR, MNR and controls respectively $(n=18$ for each group), with the weight of the MNR animals being significantly lighter $(P<0 \cdot 001)$ than that of the MR and control animals. Animals were housed 5-6 per cage, with free access to standard Purina rat chow and water. Light/dark cycle 12:12 with onset of light phase at $0700 \mathrm{~h}$. All experiments were carried out between 1000 and $1200 \mathrm{~h}$.

\section{Stress experiments}

Five animals of each strain (MR, MNR and control) were subjected to acute stress (30 min restraint stress) while stress-control animals remained untouched for this period. All animals were killed by rapid decapitation after stunning, and trunk blood was collected in heparin-coated tubes (Becton Dickinson Vacutainer Systems, Oxford, UK) and immediately centrifuged ( $200 \boldsymbol{g}$ for $10 \mathrm{~min}$ at $4{ }^{\circ} \mathrm{C}$ ). Plasma samples were stored frozen at $-20{ }^{\circ} \mathrm{C}$ awaiting steroid and peptide measurement.

\section{ACTH (1-24) treatment of dispersed adrenal cells}

MR and MNR animals were killed rapidly by stunning followed by cervical dislocation. In order to permit direct comparison between strains, cell experiments were carried out simultaneously on the two strains. Adrenals were collected in ice-cold Krebs-Ringer bicarbonate solution (KRBG), $\mathrm{pH} 7 \cdot 4\left(3.6 \mathrm{mmol} / 1 \mathrm{~K}^{+}\right)$, cleaned of adhering fat and weighed. Each gland was squashed between glass plates, and tissue was dispersed as previously described (Kapas et al. 1992), except that capsule fractions were not separated from inner adrenocortical tissue. Briefly, adrenal cells were incubated in KRBG buffer containing glucose $(200 \mathrm{mg} / 100 \mathrm{ml})$ and BSA $(200 \mathrm{mg} / 100 \mathrm{ml})$ (KRBGA) and $2 \mathrm{mg}$ collagenase $/ \mathrm{ml}$ for $1 \mathrm{~h}$ at $37^{\circ} \mathrm{C}$ under an atmosphere of $95 \% \mathrm{O}_{2}$ and $5 \% \mathrm{CO}_{2}$. Tissue was dispersed by repeated pipetting, and filtered through nylon gauze. Suspensions were centrifuged at $100 \boldsymbol{g}$ and the supernatant was discarded. After dispersion of adrenal tissue, cell counts were carried out with a haemocytometer so that equal numbers of cells from the two strains could be incubated. We incubated $10^{6}$ adrenal cells in $1 \mathrm{ml}$ KRBGA for $1.5 \mathrm{~h}$ under an atmosphere of $95 \% \mathrm{O}_{2}$ and $5 \% \mathrm{CO}_{2}$ in the absence or presence of $\mathrm{ACTH}$ (1-24) (Synacthen).

\section{Adrenal gene quantitation}

Animals were killed as described in the preceding section, and paired adrenal glands were rapidly removed and cleaned of adhering fat and stored in liquid nitrogen awaiting mRNA extraction (Quickprep Micro mRNA purification kit; Amersham Pharmacia Biotech), DNase treatment (Amplification Grade DNase I kit, Invitrogen) 
Table 1 Sequences of forward and reverse primers used for the PCR experiments

\begin{tabular}{|c|c|c|}
\hline \multirow[b]{2}{*}{ Gene } & Sense sequence $\left(5^{\prime}-3^{\prime}\right)$ & Antisense sequence $\left(5^{\prime}-3^{\prime}\right)$ \\
\hline & & \\
\hline NPY & ССТGTСССАСССААТGСА & CAACGACAACAAGGGAAATGG \\
\hline GAPDH & TGCACCACCAACTGCTTAG & GGATGCAGGGATGATGTTC \\
\hline
\end{tabular}

and cDNA synthesis (First Strand cDNA Synthesis Kit). Gene quantitation was done by real-time PCR through a dual-labeled fluorogenic probe (TaqMan). The probe was labeled with the fluorescent reporter dye FAM (6-carboxyfluorescein) and with the quencher dye TAMRA (6-carboxy-tetramethylrhodamine). Real-time PCR was performed by amplifying duplicate samples, containing approximately $400 \mathrm{ng}$ target cDNA, in a 10 or $20 \mu \mathrm{l}$ reaction with TaqMan PCR Core Kit reagents (Applied Biosystems, Warrington, UK). MX4000 realtime multiplex quantitative PCR was the detection system used (Stratagene, Amsterdam, the Netherlands).

Primers were designed for the genes encoding tyrosine hydroxylase, neuropeptide Y (NPY) pro-opiomelanocortin and the melanocortin receptors $\mathrm{MC} 2 \mathrm{R}$ and MC5R. Of all the genes investigated, only NPY showed significant differences between strains. The sequence of the forward and reverse rat NPY primers is presented in Table 1, and the probe sequence in Table 2. Sequences were designed with the real-time PCR software Primer Express (Applied Biosciences, Warrington, UK). NPY gene levels in each sample are presented as normalized amounts against the housekeeping gene GAPDH (see Tables 1 and 2 for sequences of primers and probe).

\section{Measurement of NPY}

To measure NPY peptide levels within the adrenals of the MR, MNR and control rats, paired tissues (capsules and inner zones separately) were homogenized on ice in $500 \mu \mathrm{l}$ protein extraction buffer $(10 \mathrm{mM}$ Tris- $\mathrm{HCl}(\mathrm{pH}$ 7•4), $5 \mathrm{mM}$ EDTA, $50 \mathrm{mM} \mathrm{NaCl}, 50 \mathrm{mM}$ NF, $1 \mathrm{mM}$ $\mathrm{Na}$-arthounadate, $30 \mathrm{mM} \mathrm{Na}$-pyrophosphate, $10 \mathrm{mM}$ benzamidine, $1 \% \mathrm{v} / \mathrm{v}$ Triton X-100, $1 \mathrm{mM} \mathrm{PMSF}$ and $5 \mu \mathrm{l} / \mathrm{ml}$ protein inhibitor cocktail) ( $\mathrm{pH} 8$ ). The homog-

Table 2 Sequences of the probes used during the gene quantitation experiments

$$
\text { Probe sequence }\left(5^{\prime}-3^{\prime}\right)
$$

$\begin{array}{ll}\text { Gene } & \\ \text { NPY } & \text { CCACCACCAGGCTGGATTCCGA } \\ \text { MC2R } & \text { CATCTTCCATGCCCTGCAATAC } \\ \text { MC5R } & \text { TACGCCCTGCGCTACCACCACA } \\ \text { POMC } & \text { CCGGATACCGAGAAGGCCGAC } \\ \text { Tyrosine hydroxylase } & \text { GCAGCAGCAGCAGCGGTAGCCT } \\ \text { GAPDH } & \text { CAGAAGACTGTGGATGGCCCT }\end{array}$

www.endocrinology-journals.org enate was sonicated $(2 \times 5 \mathrm{~s})$ on ice and then centrifuged at $3000 \mathrm{~g}$ for $10 \mathrm{~min}$ at $4{ }^{\circ} \mathrm{C}$. Total protein content of the capsules and inner zones separately was measured by the Bio-Rad protein assay based on the colour change of Coomassie Brilliant Blue G-250 (Bio-Rad Laboratories. Absorbencies of the tissue preparations were counted at $510 \mathrm{~nm}$ with a PU 8625 UV/VIS spectrophotometer. NPY peptide levels in paired adrenal tissues were measured by the human/rat EURIA-NPY RIA kit (Malmö, Sweden).

\section{Hormone measurement}

Aldosterone levels were measured, as previously described (Kapas et al. 1992), by in-house RIA. Corticosterone levels were measured by the rat RIA kit (ICN, Basingstoke, Hampshire, UK), and ACTH levels by the human IRMA kit (IDS, Bolton, UK).

\section{Results}

Direct comparison of paired adrenal weights was found that the MR strain had significantly larger adrenals than either MNR or the control Wistars $(P<0 \cdot 05)$ (Fig. 1). However, the MR animals were larger than the other groups, and when adrenal weight was corrected for body

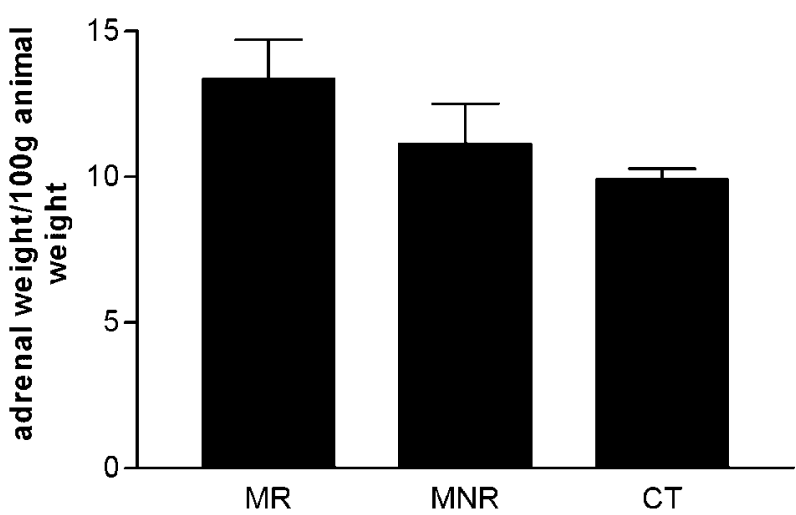

Figure 1 Adrenal weights of Maudsley and control Wistar strains. The MR strain was shown to have significantly larger adrenals than both the MNR and control strains. However, no significant difference was observed in the adrenal weights of age-matched males when values were standardized for body weight (data not shown). Values are means \pm S.E.M., $n=6$. ${ }^{*} P<0 \cdot 05$ (ANOVA). 
size, this difference was no longer significant (data not shown).

Basal levels of corticosterone, aldosterone and ACTH showed no significant differences between strains (Fig. 2).

Restraint stress of 30 min caused significant increments in circulating levels of corticosterone (Fig. 2A), aldosterone (Fig. 2B) and ACTH (Fig. 2C) in MR, MNR and control strains. It was found that corticosterone levels increased twofold in response to stress, while aldosterone increased approximately ninefold. No strain differences were observed for the steroid results. In contrast, although ACTH levels were significantly increased in response to stress in each strain, the increment was greatest for the MR strain and least for the MNR (Fig. 2C). As a result, ACTH levels in response to stress were significantly higher in MR than control animals, and significantly lower in MNR than in control animals. Corticosterone and aldosterone increased to a comparable extent in each of the strains, suggesting that the adrenals of MR animals are less sensitive and the adrenals of MNR more sensitive to ACTH stimulation.

These results were supported by experiments on the effect of ACTH on aldosterone and corticosterone output of dispersed adrenal cells of MR and MNR strains (Fig. 3). Basal secretion rates of corticosterone and aldosterone were not significantly different between MR and MNR strains (Fig. 3). ACTH caused a dose-dependent increase in aldosterone and corticosterone secretion with a 10-fold lower threshold value for the MR animals as far as aldosterone secretion was concerned, and the same threshold concentration for corticosterone secretion for both strains. However, there was a significant difference between strains in terms of maximal secretion rates of both aldosterone and corticosterone, the ACTH-stimulated MNR cells secreting significantly more steroid than the MR (Fig. 3A and B).

Adrenal NPY gene expression was found to be about three times higher in MR than MNR animals, with control Wistars intermediate between the two Maudsley strains (Fig. 4). Adrenal NPY gene expression was significantly higher in MR and lower in MNR than in control Wistars. Expression of the other genes investigated (MR2R, MC5R, tyrosine hydroxylase and POMC) showed no differences between strains (data not shown).

The pattern observed in adrenal NPY gene expression among the strains was found to be present at the protein level as well, with higher NPY peptide content of MR than MNR adrenals (Fig. 5).

\section{Discussion}

This study has added three new parameters in the investigation of the endocrinology of the Maudsley strains. It is the first study to compare the physiology of the MR and MNR strains with that of control Wistars, the ancestor of
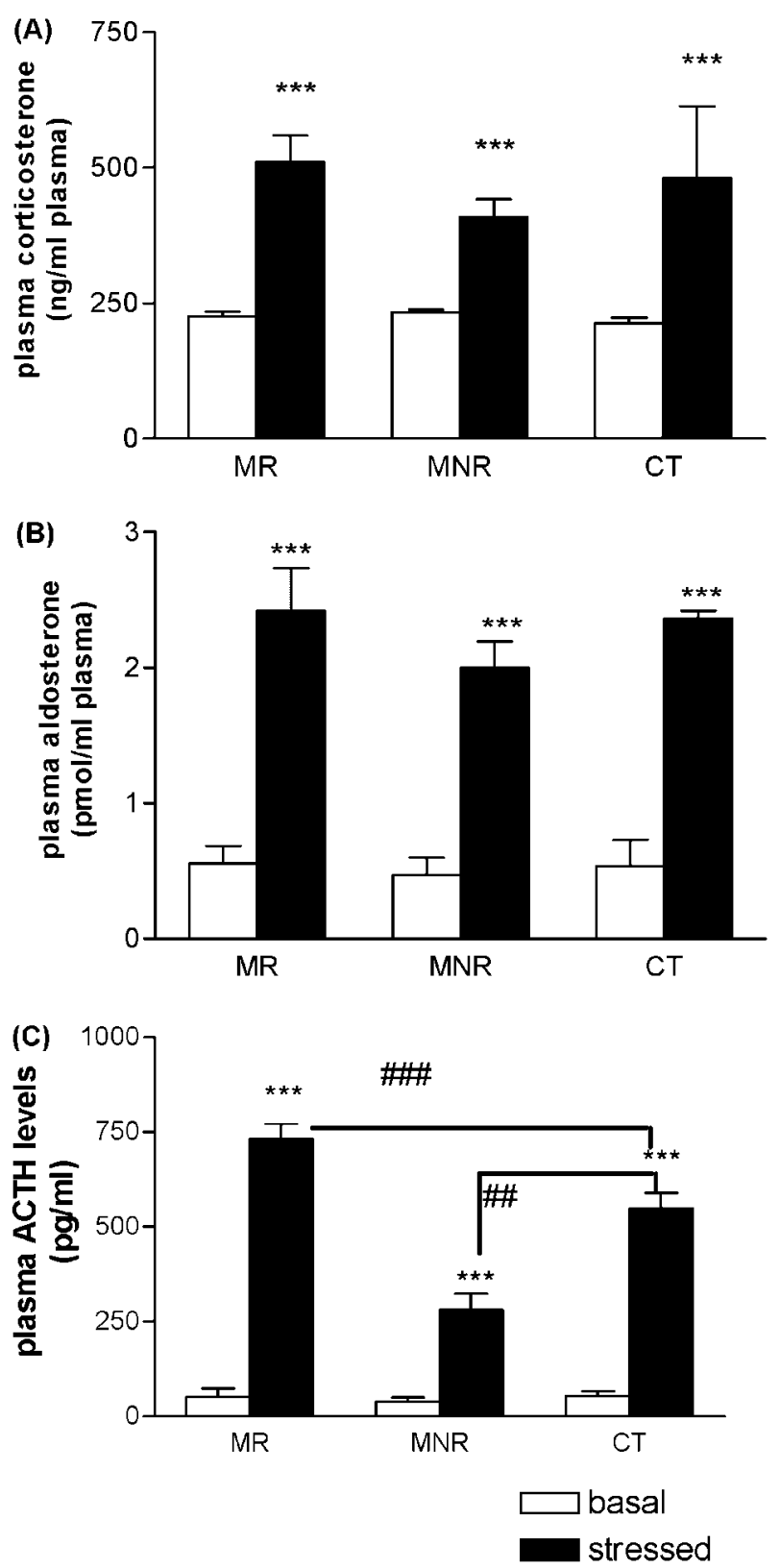

Figure 2 Plasma hormone levels after 30 min restraint stress. Male MR, MNR and control strains responded to 30 min restraint stress with significant increases in (A) plasma corticosterone levels, (B) plasma aldosterone and (C) plasma ACTH. There were no differences apparent between strains in terms of steroid secretion, but ACTH levels after stress were significantly higher in the plasma of MR than of MNR, while those of control Wistars were at the middle of the two extremes of emotionality. Values are means \pm S.E.M., $n=5$. ${ }^{* *} P<0 \cdot 001$ compared with basal levels of each strain; \#\#\# $P<0 \cdot 001, \# \# P<0.01$ compared with stressed levels of control (CT) strain (ANOVA). 

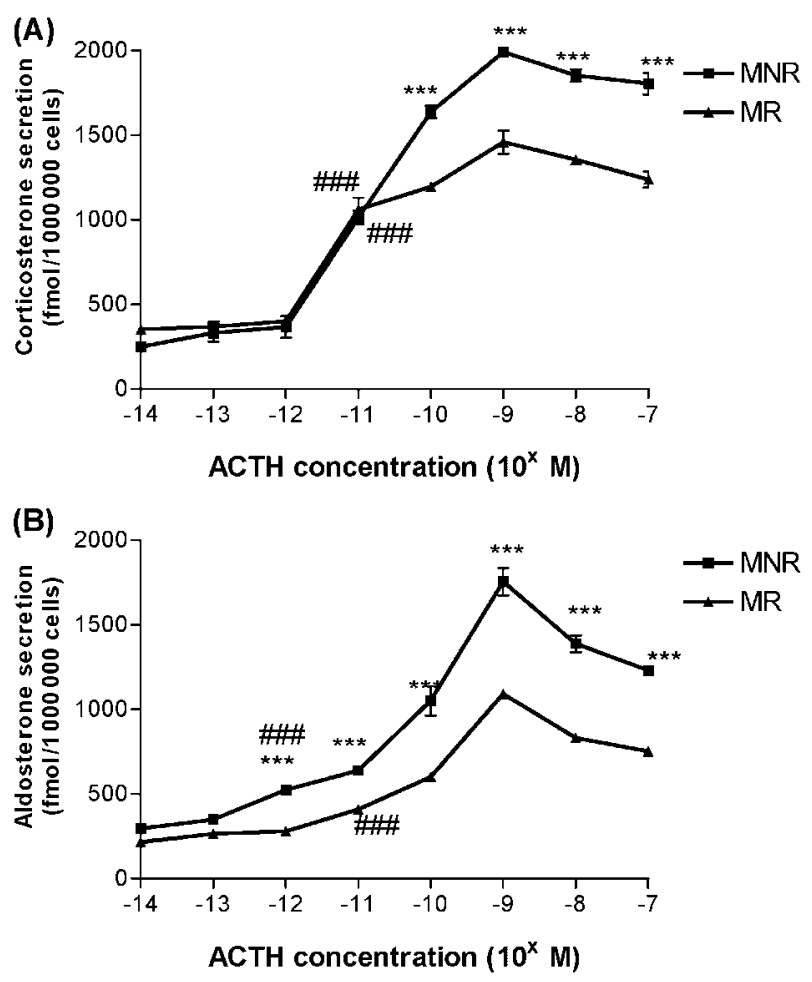

Figure 3 Corticosterone $(\mathrm{A})$ and aldosterone (B) secretion from $M R$ and MNR dispersed adrenal cells incubated in the presence of ACTH. Values are means \pm S.E.M.; $n=4$ different adrenal cell preparations. ${ }^{* * *} P<0.001$ compared with same ACTH concentration steroid secretion from the MR. \#\#\# Indicates threshold concentration for significant stimulation above basal $P<0.001$ compared with basal steroid secretion of the same strain. Steroid secretion remained significantly higher $(P<0 \cdot 001)$ for all concentrations used after threshold value (ANOVA).

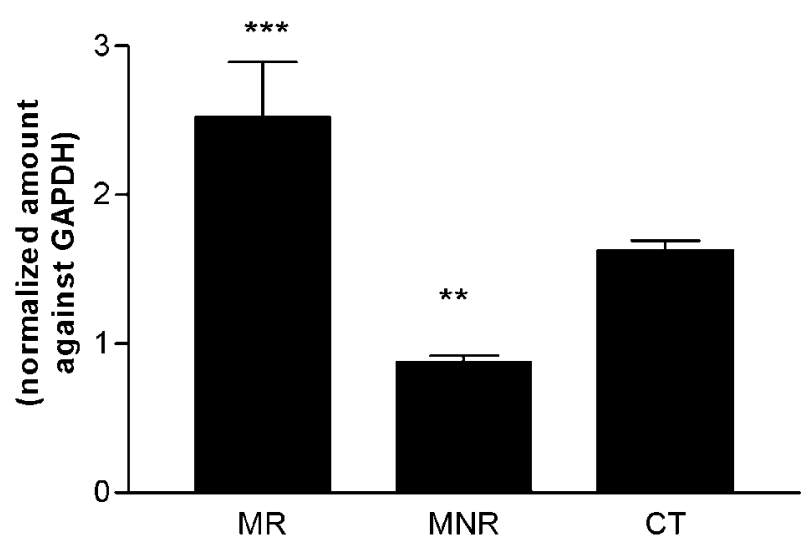

Figure 4 Comparative levels of adrenal NPY gene expression among male Maudsley and control (CT) strains. Levels were higher in MR than MNR strains, while that of control Wistars was in the middle of the two extremes. Values are means \pm S.E.M.; $n=5$ per group; experiment repeated three times. ${ }^{* *} P<0 \cdot 001 ;{ }^{*} P<0 \cdot 01$ (ANOVA)

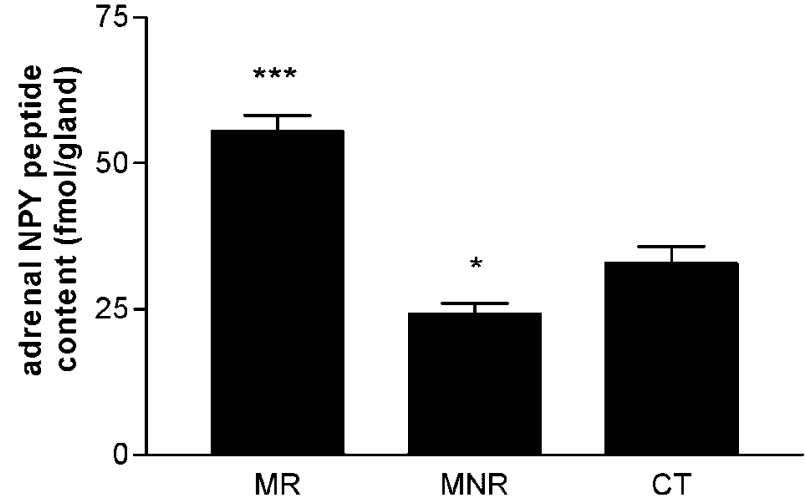

Figure 5 NPY peptide levels in the adrenals of Maudsley and control Wistar (CT) animals. As with NPY gene expression, NPY peptide levels were higher in the adrenals of MR than MNR. Values are means \pm S.E.M.; $n=8 .{ }^{* *} P<0 \cdot 001$ compared with CT (ANOVA).

the two strains. Moreover, most general research related to stress has focused on the well-recognized changes at the hypothalamic level (Francis et al. 1996, Anisman et al. 1998a, 1998b, Meaney et al. 1988), with very little work directed toward the adrenal gland itself, despite the suggestion that adrenal changes underpin strain differences in stress responses (Gomez et al. 1996). As far as research on the Maudsleys is concerned, no study has focused on intra-adrenal changes following stress. Finally, this is the first study to investigate differences in the response to prolonged (30 min), acute stress in Maudsleys.

In terms of basal plasma levels of steroids, there were no differences between the three strains investigated. It was found for all three strains that larger animals had heavier adrenals, so that when adrenal weight was normalized for body weight, no strain differences in adrenal weight was observed; however, the raw data showed that MRs had larger adrenal glands than the other two groups. Basal levels of corticosterone and ACTH were comparable between the MR and MNR strains, in agreement with previous studies (Abel 1991, Blizard \& Adams 2002). Despite the relatively high basal plasma corticosterone levels detected in the animals of this study compared with the basal rat plasma corticosterone reference values (Vinson et al. 1992), 30 min restraint stress caused significant increments in both corticosterone and aldosterone levels in all three strains $(P<0 \cdot 001)$. Although aldosterone per se is not directly involved in HPA axis activity, its secretion provides an additional index of the effects of ACTH on the different zones of the adrenal cortex. No strain differences were observed in the aldosterone or corticosterone response to restraint stress.

In contrast to the results obtained with the steroid hormones, there were significant differences in the ACTH response to prolonged stress between the strains. Taking the Wistar strain as 'control', we found that the MR strain 
showed a larger increment in the ACTH response to stress while the MNR strain showed an attenuated ACTH response to stress. This is the first study that reveals differences in stressed ACTH levels between the MR and MNR animals when tested after acute stress. Previous studies reported that basal and stressed ACTH levels were comparable between the strains (Abel 1991, Blizard \& Adams 2002). One possible explanation is that differences in the physiology of animal stocks when bred in different facilities are common. However, the MR and the MNR animals used in this study were evaluated to ensure accuracy of phenotype, and similar precautions are reported by authors of other studies. Perhaps more significantly, it has previously been observed that acute stress challenges that are not considered to be strongly stressful (such as the open-field test) have resulted in smaller increments in corticosterone levels than more stressful tests (such as the forced-swim stress) (Blizard \& Adams 2002). Based on this observation, we could consider another scenario to explain our result: it is possible that the 30 min restraint stress can reveal aspects of the HPA axis that remain concealed when acute stress paradigms of shorter duration (10 min swim stress, $10 \mathrm{~min}$ open-field test and foot shock) are used. That is, although a shortlasting acute stress test equally increases ACTH plasma levels in the two Maudsley strains, a longer-lasting stress test further increases ACTH levels, revealing the strain differences. To the best of our knowledge, no study has compared the $30 \mathrm{~min}$ restraint stress, $10 \mathrm{~min}$ swim stress and 10 min open-field stress for robustness of HPA axis activation.

All three strains respond to stress in a similar manner, as shown by the end point of the HPA axis; that is, they achieve similar levels of corticosterone and aldosterone release. However, the MR animals present with an exaggerated ACTH response to stress, as they secrete twice as much ACTH to stimulate their adrenals as the MNR. Normal rat adrenals (control Wistars) show an ACTH response to stress that is intermediate between the MR and MNR strains. These observations imply a loss of sensitivity of the adrenals of the MR animals, accompanied by oversensitivity of the adrenals of the MNR animals relative to the control Wistar strain. Indeed, stimulation of dispersed cells isolated from the adrenals of MR and MNR animals demonstrated that the cells originating from the MNR adrenals required smaller amounts of ACTH $\left(10^{-12} \mathrm{M}\right)$ to increase aldosterone levels significantly above basal compared with those of MR adrenals $\left(10^{-11} \mathrm{M}\right)$. Moreover, although the maximum effect in both aldosterone and corticosterone secretion from dispersed cells of both strains was achieved at the concentration of ACTH of $10^{-9} \mathrm{M}$, the increment in steroid secretion was significantly higher in the dispersed cells of the MNR strains $(P<0 \cdot 001)$ for both aldosterone and corticosterone release. This finding supports the hypothesis that the adrenals of the MR strain have a diminished sensitivity to stimulation with ACTH, while the MNR have increased sensitivity.

The finding of differential sensitivity to ACTH between the MR and MNR strains may have considerable implications for the animals' adaptive stress response. According to a recent report (Weiss et al. 2004), experiments to assess the capacity of cows to cope with changes in milking patterns found animals with higher adrenal cortex sensitivity to be more efficient in the adaptation processes. Adrenal sensitivity was judged by increased cortisol release after ACTH injection. According to this model, MNR animals that have a higher adrenal sensitivity would also cope better with stressful situations, as shown by the low defecation scores in the open-field test. On the other hand, MR animals with low adrenal sensitivity show an exaggerated and less adaptive response to stress. We should note that although data gained from this study suggest that the adrenals of the MR animals require higher amounts of ACTH to stimulate their adrenals at the same level as those of control Wistar rats and MNR, that is, they are less responsive, we need to be cautious in interpreting the results obtained from a single sampling point. For full evaluation of the regulation of the HPA system, different sampling points for corticosterone and ACTH should be introduced during the stress procedure.

It has previously been suggested that the effects of sex and strain on responsiveness to ACTH may be due to differences in the amount of an intra-adrenal inhibitor of steroidogenesis (Vinson et al. 1978). Previous research from our laboratory has been directed toward the elucidation of intra-adrenal mechanisms regulating adrenocortical function. Accordingly, we addressed the question as to whether there are strain differences in intraglandular regulators that may account for the differences seen in adrenal sensitivity to ACTH. Of the factors tested, only NPY expression showed any difference between strains.

Previous studies, from our laboratory and others, have investigated the role of various neurotransmitters identified within the adrenal gland, and reported that NPY appears to have an inhibitory effect on steroid secretion, particularly in response to ACTH (Malendowicz et al. 1990, Hinson et al. 1995). It has been demonstrated that NPY both inhibits basal secretion rates (Malendowicz et al. 1990) and causes attenuation of the response to high concentrations of ACTH, an effect shown to be mediated by a diminished cAMP response (Hinson et al. 1995). In addition, long-term treatment of rats with NPY causes a decrease in zona fasciculata cell size, with an inhibitory effect on corticosterone secretion as measured by adrenal corticosterone content (Lesniewska et al. 1990). It should be noted that not all studies have found that NPY inhibits rat adrenal function: there are contradictory reports published, often from the same research group (for reviews, see Renshaw \& Hinson 2001, Spinazzi et al. 2005). The findings of the present study, that adrenal levels of 
NPY mRNA and peptide are higher than controls in the MR strain and lower in the MNR strain, suggest that the suppression of the corticosterone response to ACTH in the MR strain may be due to the higher levels of NPY present in this strain.

NPY in the rodent adrenal is actively regulated and is known to be increased by various forms of acute and chronic stress, including fasting (Chua et al. 1991), cold (Hiremagalur et al. 1994), immobilization (Nankova et al. 1996) and shaker stress (Levenson and Moore 1998). Adrenal NPY could be argued to be a 'stress-marker' in rats. The present study found NPY gene expression to be greater $(P<0 \cdot 001)$ in the adrenals of MR than MNR, while that of controls was in the middle of that of the two Maudsley strains. If we view NPY as a 'stress molecule', this finding may suggest that the MR animals are constantly in a state of stress compared with control rats, and even more so when compared with their MNR counterparts. It is most unlikely that the 'stress' effects on adrenal NPY are a result of increased ACTH secretion, as previous studies have shown that ACTH administration causes a decrease in adrenal NPY content (Hinson et al. 1998). It is therefore likely that alterations in adrenal NPY content may be the primary cause of the differences in HPA function between these rat strains. This is entirely consistent with reports that adrenal NPY synthesis and release is controlled by the sympathetic input to the gland (Allen et al. 1984, Gaumann et al. 1989).

To conclude, these strains of rats, bred for their differences in defecation when exposed to mild stress, appear to represent the extremes of a chronic rat stress model. Although there are no differences in their basal plasma hormone levels, there is evidence of a subtle change in adrenal responsiveness to stress stimulation, such that the response to the MR strain appears to be damped down relative to both controls and the MNR strain. We hypothesize that differences in intra-adrenal NPY content may be an adaptive response to chronic stress, and this could account for the observed differences in adrenal responsiveness. In the light of the data obtained from the study on dairy cattle, in which the animals with adrenals more sensitive to stimulation were better able to adapt to change (Weiss et al. 2004), it is likely that this adrenal adaptive change seen in the MR strain may, in fact, be maladaptive, as it may reduce the capacity of the individual to respond appropriately to acute (additional) stress. This study not only demonstrates altered adrenal function in this genetic model of emotionality, but also encourages further work that may lead to better understanding of the endocrinology of stress disorders.

\section{Acknowledgements}

This work was supported by a project grant award by the Special Trustees of St Bartholomew's Hospital. We gratefully thank Dr John Stamford and Farah Ahmed for the donation of the Maudsley animals. The authors declare that there is no conflict of interest that would prejudice the impartiality of this scientific work.

\section{References}

Abel EL 1991 Behaviour and corticosteroid response of Maudsley reactive and nonreactive rats in the open field and forced swimming test. Physiological Behaviour 50 151-153.

Ader R, Friedman SB \& Grota LJ 1967 'Emotionality' and adrenal cortical function: effects of strain, test, and the 24-hour corticosterone rhythm. Animal Behavior 15 37-44.

Allen JM, Bircham PMM, Bloom SR \& Edwards AV 1984 Release of neuropeptide $\mathrm{Y}$ in response to splanchnic nerve stimulation in the conscious calf. Journal of Physiology 357 401-408.

Anisman H, Lacosta S, Kent P, McIntyre DC \& Merali Z 1998 a Stressor-induced corticotropin-releasing hormone, bombesin, ACTH and corticosterone variations in strains of mice differentially responsive to stressors. Stress 2 209-220.

Anisman H, Zaharia MD, Meaney MJ \& Merali Z $1998 b$ Do early-life events permanently alter behavioral and hormonal responses to stressors? International Journal of Developmental Neuroscience 16 149-164.

Blizard DA \& Adams N 2002 The Maudsley reactive and nonreactive strains: a new perspective. Behavioural Genetics 32 277-299.

Broadhurst PL 1957 Determinants of emotionality in the rat. I. Situational factors. British Journal of Psychiatry 48 1-12.

Chua SC, Leibel RL \& Hirsch J 1991 Food deprivation and age modulate neuropeptide gene expression in the murine hypothalamus and adrenal gland. Molecular Brain Research 9 95-101.

Francis D, Diorio J, LaPlante P, Weaver S, Seckl JR \& Meaney MJ 1996 The role of early environmental events in regulating neuroendocrine development. Annals of the New York Academy of Sciences 794 136-152.

Gaumann DM, Yaksh TL, Tyce GM \& Stoddard SL 1989 Adrenal vein catecholamines and neuropeptides during splanchnic nerve stimulation in cats. Peptides 10 587-592.

Gomez F, Lahmame A, de Kloet ER \& Armario A 1996 Hypothalamic-pituitary-adrenal response to chronic stress in five inbred rat strains: differential responses are mainly located at the adrenocortical level. Neuroendocrinology 63 327-337.

Hinson JP, Cameron LA \& Kapas S 1995 Neuropeptide Y modulates the sensitivity of the rat adrenal cortex to stimulation by ACTH. Journal of Endocrinology 145 283-289.

Hinson JP, Renshaw D, Cruchley AT \& Kapas S 1998 Regulation of rat adrenal neuropeptide Y (NPY) content: effects of ACTH, dexamethasone and hypophysectomy. Regulatory Peptides 75 175-180.

Hiremagalur B, Kvetnansky R, Nankova B, Fleischer J, Geertman R, Fukuhara K, Viskupic E \& Sabban EL 1994 Stress elicits trans-synaptic activation of adrenal neuropeptide $\mathrm{Y}$ gene expression. Molecular Brain Research 27 138-144.

Kapas S, Orford CD, Barker S, Vinson GP \& Hinson JP 1992 Studies on the intracellular mechanism of action of alpha-melanocytestimulating hormone on rat adrenal zona glomerulosa. Journal of Molecular Endocrinology 9 47-54.

Lesniewska B, Nowak M, Miskowiak B \& Nussdorfer GG 1990 Long-term effects of neuropeptide $\mathrm{Y}$ on the rat adrenal cortex. Neuropeptides 16 9-13.

Levenson CW \& Moore JB 1998 Response of rat adrenal neuropeptide $\mathrm{Y}$ and tyrosine hydroxylase mRNA to acute stress is enhanced by long-term voluntary exercise. Neuroscience Letters 242 177-179. 
Malendowicz LK Lesniewska B \& Miskowiak B 1990 Neuropeptide $\mathrm{Y}$ inhibits corticosterone secretion by isolated adrenocortical cells. Experientia 46 721-722.

Meaney MJ, Aitken DH, van Berkel C, Bhatnagar S \& Sapolsky RM 1988 Effect of neonatal handling on age-related impairments associated with the hippocampus. Science 239 766-768.

Nankova B, Kvetnansky R, Hiremagalur B, Sabban B, Rusnak M \& Sabban EL 1996 Immobilisation stress elevates gene expression for catecholamine biosynthetic enzymes and some neuropeptides in rat sympathetic ganglia: effects of adrenocorticotropin and glucocorticoids. Endocrinology 137 5597-5604.

Renshaw D \& Hinson JP 2001 Neuropeptide Y and the adrenal gland: a review. Peptides 22 429-438.

Spinazzi R, Andreis PG \& Nussdorfer GG 2005 Neuropeptide Y and Y-receptors in the autocrine-paracrine regulation of adrenal gland under physiological and pathophysiological conditions. International Journal of Molecular Medicine 15 3-13.
Vinson GP, Whitehouse BJ \& Goddard C 1978 The effect of sex and strain on the in vitro response of adrenocortical tissue to ACTH stimulation. Journal of Steroid Biochemistry 9 553-560.

Vinson GP, Whitehouse BJ \& Hinson JP 1992 The Adrenal Cortex. Prentice-Hall Endocrinology Series. Englewood Cliffs, NJ, USA: Prentice-Hall.

Weiss D, Helmreich S, Mostl E, Dzidic A \& Bruckmaier RM 2004 Coping capacity of dairy cows during the change from conventional to automatic milking. Journal of Animal Science 82 563-570.

Yeakel EH \& Rhoades RP 1941 A comparison of the body and endocrine gland (adrenal, thyroid and pituitary) weights of emotional and nonemotional rats. Endocrinology 28 357-340.

Received in final form 13 January 2006 Accepted 24 January 2006 